\title{
Numerical Study of Unsaturated Infinite Slope Stability regarding Suction Stress under Rainfall-induced Infiltration Conditions
}

\author{
Young-Suk Song ${ }^{1, *}$ and Woong-Ki Hwang ${ }^{2}$ \\ ${ }^{1}$ Korea Institute of Geoscience and Mineral Resources, Geological Hazards Department \\ ${ }^{2}$ Korea Maritime and Ocean University, Department of Civil Engineering
}

\begin{abstract}
Numerical stability analysis of an unsaturated infinite slope under rainfall-induced infiltration conditions was performed using generalized effective stress to unify both saturated and unsaturated conditions The soil-water characteristic curve (SWCC) of sand with a relative density of $75 \%$ was initially measured for both drying and wetting processes. The hydraulic conductivity function (HCF) and suction stress characteristic curve (SSCC) were subsequently estimated. Under the rainfall-induced infiltration conditions, transient seepage analysis of an unsaturated infinite slope was performed using the finite element analysis program, SEEP/W. Based on these results, the stability of an unsaturated infinite slope under rainfall-induced infiltration conditions was examined in relation to suction stress. According to the results, the negative pore-water pressure and water content within the slope soil changed over time due to the infiltration. In addition, the variation of the negative pore-water pressure and water content led to a variation in suction stress and a subsequent change in the slope's factor of safety during the rainfall period.
\end{abstract}

Key words : Unsaturated infinite slope, Rainfall-induced infiltration, Transient seepage analysis, Suction stress, Factor of safety

\section{Introduction}

Most of the recent landslides in Korea occurred via translational slides within $2 \mathrm{~m}$ of the ground surface (Kim et al., 2007). In other words, most landslides occurred due to rainfall-induced infiltration and were mainly shallow failures (Song et al., 2012a; Song, 2013). The fundamental cause of such slope failure is an increased degree of saturation in the vadose zone and reduced matric suction due to precipitation. Consequently, the suction changes over time and the factor of safety is reduced.

Therefore, this research investigated the effect of suction variation caused by rainfall-induced infiltration on the stability of an unsaturated infinite slope. To do this, we used a new effective stress concept that includes suction stress, as proposed by Lu and Likos (2004). The concept of suction stress is described in greater detail in the following section. The soil-water characteristic curve (SWCC), hydraulic conductivity function (HCF), and suction stress characteristic curve (SSCC) of Jumunjin sand were estimated using data measured by an automated soil-water characteristic curve apparatus. The variation in the matric suction was then predicted for rainfall using the infinite program, SEEP/W, and finally the variations in suction stress and slope stability were analyzed.

\section{Hydraulic characteristics of unsaturated soil}

\section{Soil-Water Characteristic Curve (SWCC)}

Knowledge of matric suction is essential in understanding flow, stress, and deformation phenomena with

*Corresponding author: yssong@kigam.re.kr

(c) 2014, The Korean Society of Engineering Geology

This is an Open Access article distributed under the terms of the Creative Commons Attribution Non-Commercial License (http://creativecommons. org/ licenses/by-nc/3.0) which permits unrestricted non-commercial use, distribution, and reproduction in any medium, provided the original work is properly cited. 


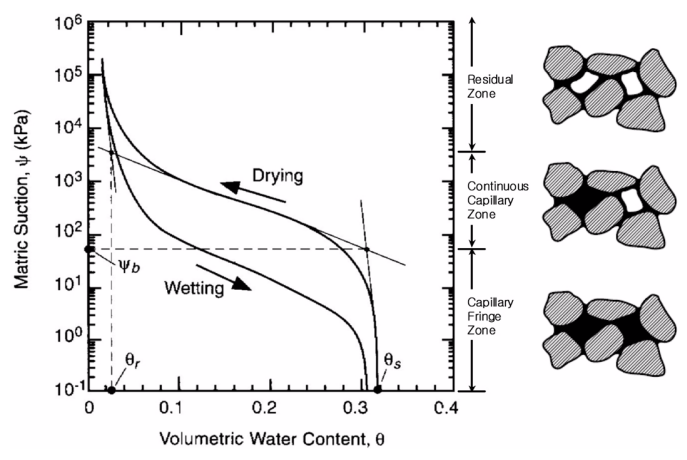

Fig. 1. A typical SWCC (modified from Lu and Likos, 2004).

respect to unsaturated soil. The SWCC is typically defined as the relationship between the matric suction and the volumetric water content of an unsaturated soil. The SWCC is, therefore, the most important property in unsaturated soil mechanics. Fig. 1 shows a typical SWCC. Water content can be expressed in terms of volumetric water content or degree of saturation, and soil suction can be expressed in terms of matric suction.

Various models have been proposed to present SWCC in continuous mathematical form. Three models in particular are commonly adopted in the field of geotechnical engineering: the Brooks and Corey (1964) model, the van Genuchten (1980) model, and the Fredlund and Xing (1994) model. According to the analytical results of Song et al. (2010), the van Genuchten (1980) model is the most reliable way to fit the relationship between matric suctions and volumetric water content in Jumunjin sand. The van Genuchten (1980) model was therefore used in this study, and may be expressed as

$$
\Theta=\frac{\theta-\theta_{r}}{\theta_{s}-\theta_{r}}=S_{e}=\frac{S-S_{r}}{1-S_{r}}=\left[\frac{1}{1+(\alpha \psi)^{n}}\right]^{m}
$$

where $\Theta$ is the normalized volumetric water content, $\theta$ is the volumetric water content, $\theta_{s}$ is the saturated volumetric water content, $\theta_{r}$ is the residual volumetric water content, $S_{e}$ is the effective degree of saturation, $S$ is the degree of saturation, $S_{r}$ is the residual degree of saturation, $\alpha, n$, and $m$ are the empirical fitting parameters, and $\psi$ is the difference between pore air pressure and pore water pressure (i.e., $u_{a}-u_{w}$ ).

\section{Hydraulic Conductivity Function (HCF)}

The relative hydraulic conductivity function $k_{r}(\psi)$ is a flexible closed-form analytical equation proposed by van Genuchten (1980) by substituting equation (1) into the statistical conductivity models proposed by Burdine (1953) and Mualem (1978), and was adopted as follows

$$
k=k_{s} k_{r}
$$

where $k_{r}=\Theta^{0.5}\left[1-\left(1-\Theta^{1 / m}\right)^{m}\right]^{2}$

This allows the hydraulic conductivity function, $k$, of unsaturated soil to be estimated directly from a corresponding model of the SWCC if the saturated hydraulic conductivity, $k_{s}$, is known.

\section{Suction Stress Characteristic Curve (SSCC)}

There are two widely recognized macroscale approaches for describing the state of stress in unsaturated soil: (1) the modified effective stress approach, which is generally attributed to the work of Bishop (1959); and (2) the independent stress state variable approach, which is generally attributed to the work of Fredlund and Morgenstern (1977).

Bishop's (1959) effective stress approach involves a modified form of Terzaghi's (1943) classic effective stress equation (3) written as follows:

$$
\begin{aligned}
& \sigma^{\prime}=\sigma-u_{w} \\
& \sigma^{\prime}=\sigma-u_{a}+\chi\left(u_{a}-u_{w}\right)
\end{aligned}
$$

where the "effective stress parameter" $\chi$ is generally considered to vary between zero and unity as a function of the degree of pore-water saturation. The difference $\left(\sigma-u_{a}\right)$ is the net normal stress and the difference $\left(u_{a}-u_{w}\right)$ is matric suction. For $\chi$ equal to zero (corresponding to perfectly dry conditions) and for $\chi$ equal to unity (corresponding to saturated conditions), equation (4) reduces to Terzaghi's effective stress. For $\chi$ between zero and unity, the second term in equation (4), $\chi\left(u_{a}-u_{w}\right)$, describes the contribution of matric suction to effective stress. Following the approach by Bishop (1959), the macroscopic engineering behavior of unsaturated soil is described using the effective stress defined by equation (4) within the established framework of saturated soil mechanics. Shear 
strength, for example, may be described by incorporating the modified effective stress expression into the classical Mohr-Coulomb failure criterion:

$$
\tau_{f}=c^{\prime}+\left[\left(\sigma-u_{a}\right)+\chi\left(u_{a}-u_{w}\right)\right]+\tan \phi^{\prime}
$$

where $c^{\prime}$ is the effective cohesion and $\phi^{\prime}$ is the effective angle of internal friction.

Following the independent stress state variable approach by Fredlund and Morgenstern (1977), net normal stress ( $\sigma-$ $\left.u_{a}\right)$ and matric suction $\left(u_{a}-u_{w}\right)$ were treated independently in terms of their roles in the mechanical behavior of unsaturated soil. Macroscopic behavior is described in terms of the independent stress state variables and conjugate material properties. Shear strength, for example, may be described as

$$
\tau_{f}=c^{\prime}+\left(\sigma-u_{a}\right) \tan \phi^{\prime}+\left(u_{a}-u_{w}\right) \tan \phi^{b}
$$

where the first two terms comprise the classical MohrCoulomb criterion and the third term introduces $\phi^{b}$ as an additional friction angle to capture the contribution of matric suction to shear strength.

The effectiveness, validity, and practicality of these two different approaches for describing the state of stress and corresponding behavior of unsaturated soil remain largely uncertain. Difficulties associated with the experimental or theoretical determination of the effective stress parameter $\chi$ have limited the general applicability of Bishop's approach in both research and practice. Experimental studies have suggested the non-uniqueness of $\chi=f(S)$. Similar experimental and conceptual difficulties associated with the determination of required material variables such as $\phi^{b}$ and uncertainties in their uniqueness over a wide range of saturation have limited the practical applicability of the independent stress variable approach ( $\mathrm{Lu}$ and Likos 2006).

$\mathrm{Lu}$ et al. (2010) recently conceptualized a closed-form equation to represent the state of effective stress in unsaturated soil by introducing the suction stress characteristic curve as equation (7).

$$
\sigma^{\prime}=\left(\sigma-u_{a}\right)-\sigma^{s}
$$

where $\sigma^{\prime}$ is the effective stress, $\sigma$ is the total stress, $u_{a}$ is the pore air pressure, and $\sigma^{s}$ is the suction stress.
The suction stress which includes van der Waals attraction, electrical double-layer repulsion, cementation forces, surface tension forces, and attractive forces arising from negative pore-water pressure ( $\mathrm{Lu}$ and Likos 2004, 2006) is expressed as equation (8).

$$
\sigma^{s}=\sigma_{p c}+\sigma_{c a p}+\chi\left(u_{a}-u_{w}\right)
$$

where $\sigma_{p c}$ is the physicochemical stress attributable to van der Waals attraction, electrical double-layer repulsion, and cementation forces, and $\sigma_{c a p}$ is the capillary stress arising from surface tension and negative pore-water pressure.

The suction stress also graphically represents the area under the normalized soil water characteristic curve and can be expressed as equation (9).

$$
\sigma^{s}=-S_{e}\left(u_{a}-u_{w}\right)
$$

where $u_{a}$ is the pore air pressure, $u_{w}$ is the pore water pressure, and $S_{e}$ is the effective degree of saturation.

A closed-form expression for suction stress for the full range of saturation can be arrived at by substituting equation (1) into equation (9) and eliminating matric suction:

$$
\sigma^{s}=-\frac{S_{e}}{\alpha}\left(S_{e}^{\frac{n}{1-n}}-1\right)^{\frac{1}{n}} \quad 0 \leq S_{e} \leq 1
$$

Similarly, a closed-form expression for suction stress for the full range of matric suction can be arrived at by substituting equation (1) into equation (9) and eliminating the degree of saturation:

$$
\begin{aligned}
& \sigma^{s}=-\left(u_{a}-u_{w}\right) \quad u_{a}-u_{w} \leq 0 \\
& \sigma^{s}=-\frac{\left(u_{a}-u_{w}\right)}{\left(1+\left[\alpha\left(u_{a}-u_{w}\right)\right]^{n}\right)^{(n-1)^{\prime n}}} \quad u_{a}-u_{w} \geq 0
\end{aligned}
$$

Substituting equation (11) into equation (7), the closedform equation for effective stress in the entire pore water pressure range (fully saturations) is

$$
\begin{aligned}
& \sigma^{\prime}=\sigma-u_{a}+\left(u_{a}-u_{w}\right) \quad u_{a}-u_{w} \leq 0 \\
& \sigma^{\prime}=\sigma-u_{a}+\frac{\left(u_{a}-u_{w}\right)}{\left(1+\left[\alpha\left(u_{a}-u_{w}\right)\right]^{n}\right)^{(n-1) / n}} \quad u_{a}-u_{w} \geq 0
\end{aligned}
$$


Table 1. Physical properties of Jumunjin sand.

\begin{tabular}{lccc}
\hline \multicolumn{1}{c}{ Property } & \multicolumn{2}{c}{ Symbol } & Value \\
\hline Specific gravity & \multicolumn{2}{c}{$G_{\mathrm{s}}$} & 2.62 \\
Max. dry unit weight & $\gamma_{\mathrm{dmax}}$ & $\mathrm{kN} / \mathrm{m}^{3}$ & 15.82 \\
Min. dry unit weight & $\gamma_{\mathrm{dmin}}$ & & 13.40 \\
Effective particle size & $D_{10}$ & $\mathrm{~mm}$ & 0.42 \\
$D_{30}$ particle size & $D_{30}$ & 0.51 \\
$D_{60}$ particle size & $D_{60}$ & 0.63 \\
Uniformity coefficient & \multicolumn{2}{c}{$C_{\mathrm{u}}$} & 1.50 \\
Coefficient of curvature & \multicolumn{2}{c}{$C_{\mathrm{c}}$} & 1.00 \\
Soil classification & \multicolumn{2}{c}{$\mathrm{USCS}$} & $\mathrm{SP}$ \\
Saturated hydraulic conductivity & $k_{s}$ & $\mathrm{~m} / \mathrm{hr}$ & 0.53 \\
\hline
\end{tabular}

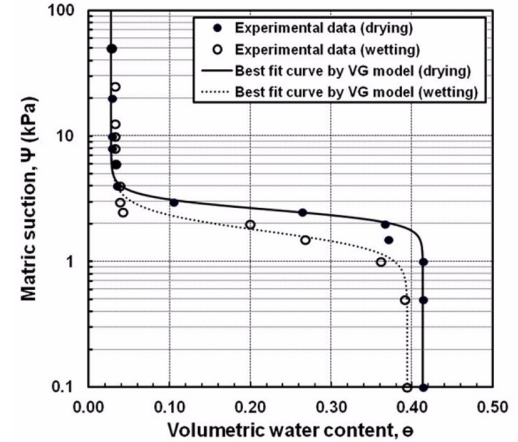

(a) Relationship between volumetric water content and matric suction

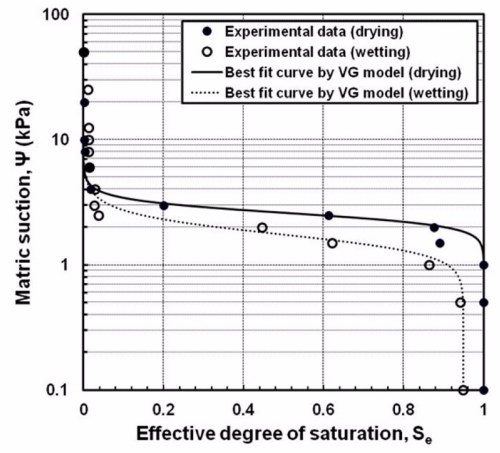

(b) Relationship between effective degree of saturation and matric suction

Fig. 2. Soil-water characteristic curves for drying and wetting processes.

Table 2. Fitting parameters used in the van Genuchten (1980) model.

\begin{tabular}{cccccc}
\hline Parameter & $\theta_{s}$ & $\theta_{r}$ & $\alpha$ & $n$ & $m$ \\
\hline Drying curve & 0.41 & 0.03 & 0.393 & 8.553 & 0.883 \\
Wetting curve & 0.39 & 0.03 & 0.593 & 5.561 & 0.820 \\
\hline
\end{tabular}

\section{Hydraulic characteristics of Jumunjin sand}

During this study, physical tests and soil-water characteristic tests were performed to estimate the soil-water characteristic curve, hydraulic conductivity function, and suction stress characteristic curve of Jumunjin sand with a relative density of $75 \%$. Table 1 lists the results of the tests.

\section{Soil-Water Characteristic Curve (SWCC)}

The relationship between matric suction and volumetric water content was measured using an automated SWCC apparatus (Song et al., 2012b). The test for measuring SWCC was conducted for both drying and wetting processes in order to examine the hysteresis of SWCC. The fitting parameters of the van Genuchten (1980) model were estimated for each test using the data measured from the experiments and a nonlinear least-squares computer program. Fig. 2 shows soil-water characteristic curves for drying and wetting processes. Table 2 lists the parameters used in van Genuchten's SWCC model. In Table 2, $\alpha$ is the parameter related to the air entry value, $n$ is the 
parameter related to the slope of SWCC, and $m$ is the parameter related to the residual water content.

As shown in Fig. 2, the hysteresis phenomenon, exemplified by different matric suctions over the same volumetric water content, was observed between drying and wetting processes and was attributed mainly to inkbottle and contact angle hysteresis. In addition, Fig. 2 shows that the inclination of the transient region (funicular zone) of the curve is extremely steep and that the matric suction corresponding to residual volumetric water content was around $4 \mathrm{kPa}$. These results are attributed to the highly uniform particle composition and narrow grain size distribution of Jumunjin sand.

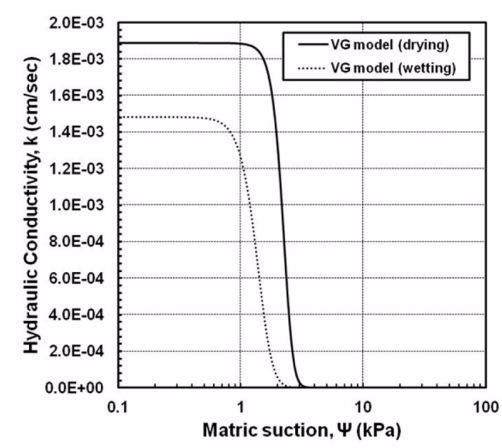

(a) Relationship between hydraulic conductivity and matric suction

\section{Hydraulic Conductivity Function (HCF)}

HCF for both drying and wetting processes was estimated using equation (2) and SWCC, as displayed in Fig. 3. Similar to SWCC, HCF was maintained until the air-entry value was obtained, followed by a rapid reduction. Significantly, the hydraulic conductivity also exhibited the hysteresis phenomenon.

\section{Suction Stress Characteristic Curve (SSCC)}

The SSCC for Jumunjin sand with a relative density of $75 \%$ was estimated for both paths using equation (9) and SWCC, as shown in Fig. 4. The SSCC shows that the suction stress ranged from $-0.65 \mathrm{kPa}$ (wetting) to approximately $-1.8 \mathrm{kPa}$ (drying) at a matric suction of 2

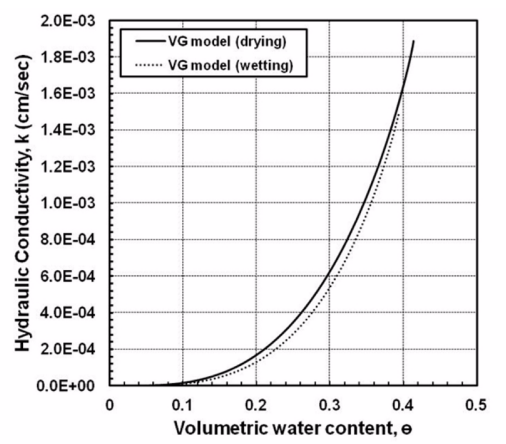

(b) Relationship between hydraulic conductivity and volumetric water content

Fig. 3. Hydraulic conductivity functions for drying and wetting processes.

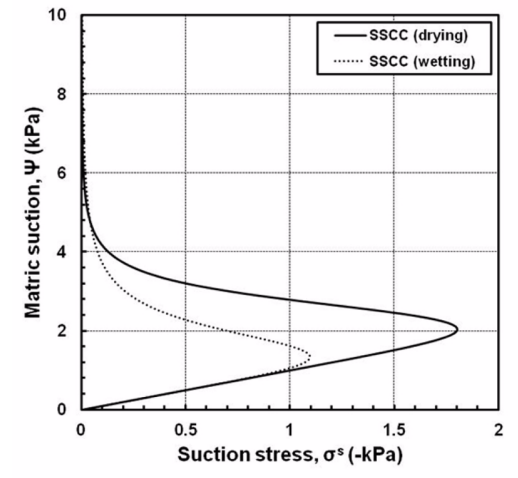

(a) Relation between suction stress and matric suction

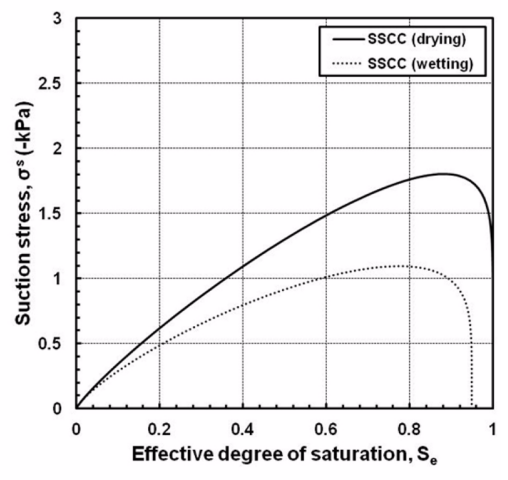

(b) Relation between suction stress and effective degree of saturation

Fig. 4. Suction stress characteristic curves for drying and wetting processes. 
$\mathrm{kPa}$, and it exhibited the hysteresis phenomenon like the SWCC and HCF. Moreover, where matric suction was less than the air-entry pressure, the suction stress decreased as the matric suction increased; however, when matric suction was greater than one, the suction stress increased to zero again as the matric suction decreased. The suction stress caused an increase in shear strength and effective stress of unsaturated soil because it had a negative value. Therefore, the suction stress aided slope stability under unsaturated conditions.

\section{Stability analysis of an unsaturated infinite slope}

The change of matric suction and volumetric water content in soils due to the rainfall-induced infiltration conditions should be considered when analyzing the stability of an unsaturated infinite slope. The transient seepage analysis was conducted using a finite element analysis program, $\mathrm{SEEP} / \mathrm{W}$, and we examined the variations in matric suction and volumetric water content within the soil over time.

For seepage analysis, we assumed a slope inclination of 1:1.5 and the geometry of the model shown in Fig. 5. In addition, it was assumed that the depth of the slope was $4.05 \mathrm{~m}$, sufficient for seepage to occur, and that the water table was located $3.05 \mathrm{~m}$ below ground level (b.g.l.). The hydraulic characteristic curve for the wetting process was also used for reproducing rainfall-induced infiltration and the rainfall condition was $0.07 \mathrm{~m} / \mathrm{hr}$ in terms of the saturated hydraulic conductivity listed in Table 3.

Seepage analysis is greatly affected by the initial state of the soil, such as the antecedent moisture conditions due to preceding rainfall levels. Therefore, in this study, it was assumed that, although the initial matric suction of the soil increased hydrostatically from the water table, the depth with maximum value was limited to $2 \mathrm{~m}$ below the ground surface. For simplicity, it was assumed that the matric suction of the region which is uppermost $0.05 \mathrm{~m}$ was $3 \mathrm{kPa}$.

The factor of safety of the unsaturated infinite slope was evaluated by limit equilibrium analysis using the generalized effective stress, which included the suction stress, as proposed by $\mathrm{Lu}$ and Likos (2004, 2006). Equation (13) was used to calculate the factor of safety of the critical sliding surface. The first term on the right hand side of the equation represents the internal frictional resistance of soil, the second term is the cohesion, and the third term is the suction stress.

$F(z)=\frac{\tan \phi^{\prime}(z)}{\tan \beta}+\frac{2 c^{\prime}}{\gamma H_{s s} \sin 2 \beta}-\frac{\sigma^{s}}{\gamma H_{s s}}(\tan \beta+\cot \beta) \tan \phi^{\prime}$

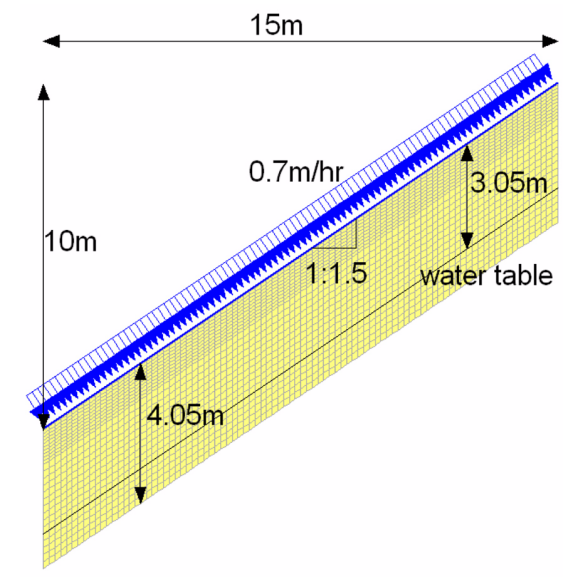

Fig. 5. Infinite slope model for the seepage analysis.

Table 3. Parameters for the stability analysis.

\begin{tabular}{|c|c|c|c|}
\hline \multirow{2}{*}{$\begin{array}{c}\text { SWCC } \\
\text { (van Genuchten parameter) }\end{array}$} & \multirow{2}{*}{ Wetting process } & $\alpha\left(\mathrm{kPa}^{-1}\right)$ & 0.593 \\
\hline & & $\mathrm{n}$ & 5.561 \\
\hline \multirow{2}{*}{ Direct shear test } & \multicolumn{2}{|l|}{$\phi^{\prime}\left(^{\circ}\right)$} & 43.27 \\
\hline & \multicolumn{2}{|l|}{$c^{\prime}(\mathrm{kPa})$} & 0 \\
\hline \multirow{2}{*}{ Slope condition } & \multicolumn{2}{|l|}{$\beta\left(^{\circ}\right)$} & $\tan ^{-1}(1 / 1.5)$ \\
\hline & \multicolumn{2}{|l|}{$H_{w t}(\mathrm{~m})$} & 3 \\
\hline Infiltration condition & \multicolumn{2}{|l|}{$q(\mathrm{~m} / \mathrm{hr})$} & 0.70 \\
\hline
\end{tabular}




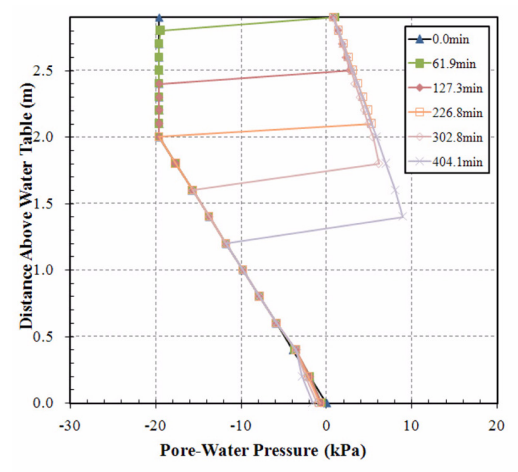

(a) Pore-water pressure

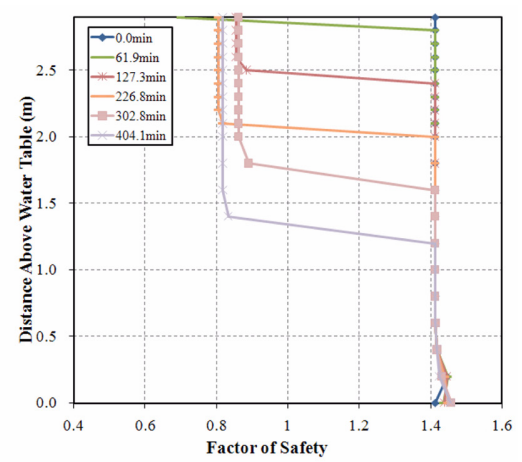

(b) Factor of safety

Fig. 6. Temporal variations in pore-water pressure and factor of safety.

where $H_{S S}$ is the distance from the ground surface to the critical failure surface, $\beta$ is the inclination of the slope, and $c^{\prime}$ and $\phi^{\prime}$ are the cohesion and the internal friction angle of soil, respectively.

Fig. 6 shows the variation in pore-water pressure and the factor of safety over time at different depths within the slope. As shown in Fig. 6, the initial distribution of porewater pressure was hydrostatically reduced in proportion to distance from the water table under the initial condition, until the pore water pressure approached approximately $-20 \mathrm{kPa}$, when it became constant. Subsequently, over time, positive pore-water pressure was generated as the pores within the soil became saturated from the ground surface due to rainfall-induced infiltration.

The initial factor of safety was 1.412 (the same as the factor of safety of the infinite slope without seepage) at more than $0.4 \mathrm{~m}$ above the water table, and slightly higher than 1.412 due to the effect of suction stress in the zone from 0 to approximately $0.4 \mathrm{~m}$ above the water table. This result is attributed to the suction stress, which helps to stabilize the slope under unsaturated conditions. However, the slope was saturated gradually due to the rainfall and then, after approximately 404 minutes, the factor of safety of the slope was 0.81 at $1.5 \mathrm{~m}$ above the water table.

\section{Conclusions}

To investigate the effect of rainfall-induced infiltration on the stability of an unsaturated infinite slope, the soil- water characteristic curves (SWCCs) of sand with a relative density of $75 \%$ were estimated for the drying and wetting processes using data measured by an automated soil-water characteristic apparatus. The unsaturated hydraulic conductivity function (HCF) and suction stress characteristic curve (SSCC) were then calculated. Consequently, the stability analysis of an unsaturated infinite slope over time and under rainfall-induced infiltration conditions was conducted by employing the limit equilibrium method, with a focus on the suction stress.

The suction stress slightly increased the factor of safety near the water table, and the maximum safety factor occurred at the location corresponding to the air-entry pressure value. Subsequently, the saturated zone was gradually formed below the ground surface over time, and, as a result, the factor of safety was rapidly reduced due to the formation of positive pore-water pressure. It was also shown that the effective range of suction stress was in the funicular zone. Therefore, the variability in matric suction and suction stress should be considered in stability analyses of unsaturated slopes.

\section{Acknowledgements}

This research was supported by the Basic Research Project (Grant No. 14-3215) of the Korea Institute of Geoscience and Mineral Resources (KIGAM) funded by the Ministry of Science, ICT, and Future Planning of Korea. 


\section{References}

Bishop, A. W., 1959, The principle of effective stress, Teknisk Ukeblad I Samarbeide Med Teknikk, 106 (39), 859-863.

Brooks, R. H. and Corey, A. T., 1964, Hydraulic properties of porous media, Colorado State University, Hydrology Paper No. 3, March, 27p.

Burdine, N. T., 1953, Relative permeability calculation from size distribution data, Transactions, American Institute of Mining, Metallurgical, and Petroleum Engineers, 198, 71-78.

Fredlund, D. G. and Morgenstern, N. R., 1977, Stress state variables for unsaturated soils, Journal of Geotechnical Engineering Division, ASCE, 103(5), 447466.

Fredlund, D. G. and Xing, A., 1994, Equations for the soil-water characteristic curve, Canadian Geotechnical Journal, 31, 521-532.

Kim, K. S., Song, Y. S., Chae, B. G., Cho, Y. C., and Lee, C. O., 2007, Geometric characteristics of landslides on natural terrain according to the geological condition, The Journal of Engineering geology, 17(1), 75-87. (in Korean)

Lu, N., Godt, J. W., and Wu, D. T., 2010, A closed-form equation for effective stress in unsaturated soil, Water Resources Research, 46, W05515.

Lu, N. and Likos, W. J., 2004, Unsaturated soil mechanics, Wiley, New York, 556pp.

Lu, N. and Likos, W. J., 2006, Suction stress characteristic curve for unsaturated soil, Journal of Geotechnical and Geoenvironmental Engineering, ASCE, 132(2), 131-142.

Mualem, Y., 1978, Hydraulic conductivity of unsaturated porous media: Generalized macroscopic approach, Water Resources Research, 14(2), 325-334.

Song, Y. S., 2013, Stability analysis of the unsaturated infinite slope considering suction stress under steady infiltration condition, Journal of Korean Geotechnical Society, 28(3), 91-100. (in Korean)

Song, Y. S., Hong, W. P. and Woo, K. S., 2012a, Behavior and analysis of stabilizing piles installed in a cut slope during heavy rainfall, Engineering Geology,
129-130, 56-67.

Song, Y. S., Hwang, W. K., Jung, S. J. and Kim, T. H., 2012b, A comparative study of suction stress between sand and silt under unsaturated conditions, Engineering Geology, 124, 90-97.

Song, Y. S., Lee, N. W., Hwang, W. K. and Kim, T. H., 2010, Construction and application of an automated apparatus for calculating the soil-water characteristic curve, Journal of Engineering Geology of Korea, 20(3), 281-295. (in Korean)

Terzaghi, K. (1943) Theoretical Soil Mechanics, John Wiley \& Sons inc., New York, 510p.

van Genuchten, M.T., 1980, A closed-form equation for predicting the hydraulic conductivity of unsaturated soils, Soil Science Society of America Journal, 44, 892-898.

Manuscript received January 14, 2014

Manuscript accepted March 11, 2014

\section{Young-Suk Song}

Korea Institute of Geoscience and Mineral

Resources, Geological Hazards Department

124 Kwahak-ro, Yuseong-gu, Daejeon 305-350

Tel: 042) 868-3035

Fax: 042) 868-3414

E-mail: yssong@kigam.re.kr

\section{Woong-Ki Hwang}

Korea Maritime and Ocean University, Department of Civil Engineering

727 Taejong-ro, Yeongdo-gu, Busan 606-791

Tel: 051) 410-4945

Fax: 051) 410-4460

E-mail: gold-a1142@nate.com 